\title{
РЕФОРМИРОВАНИЕ ГРАЖДАНСКОГО СУДОПРОИЗВОДСТВА В РОССИИ В КОНЦЕ ХIX ВЕКА: ПРИЗНАКИ СОЦИАЛИЗАЦИИ ПРОЦЕССА
}

\begin{abstract}
Аннотация: Историческое развитие гражданского прочесса в России и Европе, модели и типы гражданского процесса, развитие гражданского судопроизводства в России в конце XIX века, влияние западно-европейского гражданско-прочессуального законодательства на российское гражданскопроцессуальное законодательство; принципы гражданского процесса, их влияние на формирование моделей и типов судопроизводства; условия возрождения состязательной модели процесса и ее эволючия, проходившая путем складывания сначала либерального, а затем социального ее типов. Признаки либерального и социального типов состязательной моделей процесса; порядок применения упрощенных форм: понудительного исполнения и упрощенного гражданского судопроизводства диалектический, исторический методы, системный, сравнительно-правовой методы, анализ, синтез, дедукция, индукция, метод толкования, описание, обобщение, компаративного анализа УГС 1864 года кардинально изменил гражданское судопроизводство в России, возвратив в него состязательное начало, что, в свою очередь, привело к смене модели процесса. Исторически гражданский процесс пережил к 1864 году два цикла: состязательная модель, затем господство следственной (инквизиционной) модели и восстановление состязательной в 1864 году. Однако состязательная модель к кониу XIX века в своем развитии также прошла два этапа: этап либерального типа состязательной модели и этап социального типа состязательной модели. Первый этап - 1864 года по 1889 год, который связан с пониманием процесса как борьбы независимых сторон, каждая из которых должна была доказать свою позицию, исход дела во многом зависел от них самих. Второй этап - с 1889 года по начало XX века, когда произошло изменение понимания сущности самого процесса, законодатель стал также обращать внимание на социальную роль процесса, помогающего развитию общества и экономики, поэтому многие институты и элементы процесса были упразднены или пересмотрены.

Ключевые слова: гражданский прочесс, модели процессуальных систем, состязательный процесс, понудительное исполнение, упрощенное судопроизводство, виды производств, либеральный тип судопроизводства, сочиальный тип судопроизводства, типы состязательной модели, гражданскопроцессуальная политика.
\end{abstract}

DOI: $10.7256 / 1994-1471.2014 .6 .11086$

$Э$ волюция гражданского судопроизводства связана с развитием его моделей: следственной (инквизиционной) и состязательной. Исторически первым сформировался состязательный процесс. И.В. Решетникова указывает, что состязательная система судопроизводства возникла в Великобритании ${ }^{1}$. На наш взгляд, такой подход представляется спорным. Состязательность применялась не только в Ве-

Решетникова И.В. Судебные реформы XIX и XXI вв. в области гражданского судопроизводства // Кодификация российского частного права / под ред. Д.А. Медведева. М. 2008. С. 307. ликобритании, но и в других странах, поскольку не требовала на заре государственности от власти больших затрат, возлагая основные обязанности по защите прав на сами стороны, и устраняла публичную власть максимально от вмешательства в процесс. Источники древнерусского права указывают именно на данную модель процесса, определяя правовое положение и роль сторон в процессе. Согласно Русской Правде охрана прав - это, прежде всего, дело самозащиты и самоуправства. Гражданско-правовое разбирательство возбуждалось по инициативе заинтересованного лица подачей иска или поклепа, причем истец должен был знать

(C) Золотова Ольга Игоревна

* Соискатель кафедры теории и истории государства и права, Курский государственный университет

[olga17.10.1989@yandex.ru]

305000, Россия, г. Курск, ул. Радищева, д. 33. 
лицо, к которому предъявлял требование, а также обеспечивал его явку в суд². Стороны занимали равное положение в процессе. Они самостоятельно определяли предмет доказывания и доказательства, подтверждающие их требования и возражения. Установление фактических обстоятельств дела полностью возлагалось на них. Суд занимал нейтральную позицию и выносил решение по тому, чьи доводы в процессе были убедительнее.

Таким образом, основные принципы состязательной модели гражданского судопроизводства были выработаны еще в этот период истории государства и права и представляли собой такие начала, как диспозитивность, то есть право распоряжения сторон в процессе объектом процесса и средствами защиты, равноправие сторон, состязательность. Эти принципы эволюционировали, перечень их дополнялся, однако именно эти три основания являются столпами состязательной модели гражданского процесса.

Следующим этапом в развитии гражданского судопроизводства стало закрепление в нем следственной (инквизиционной) модели отправления правосудия. Основной его особенностью явилось закрепление возможности начала судопроизводства по инициативе самого суда. Как отмечал К. И. Малышев, «судебная власть приступает к исследованию юридических фактов и отношений по собственной инициативе или по донесениям других властей, в интересах общественного порядка и безопасности, и в самом исследовании старается раскрыть материальную истину всеми возможными способами, не стесняясь произволом и показаниями заинтересованных сторон» ${ }^{3}$. Равноправие сторон и состязательность были вытеснены. Основной задачей гражданского судопроизводства стало выяснение истины по делу, что привело к замедлению процесса разрешения споров. Кроме того, в этот период судебная власть слилась, во многом, с административной.

XIX век стал переломным моментом в истории гражданского процесса континентальной Европы и России, поскольку в этот период формировались теоретические подходы и взгляды на процедуру отправления правосудия по гражданским делам, и сейчас влияющие на нее. Кроме того, этот период связан с процессом кодификации гражданского процесса.

В этом столетии в гражданском процессе произошел ренессанс состязательной модели

Фокина М.А. Состязательный гражданский процесс в феодальной России // Правоведение. 1999. № 1. С. 106.

Малышев К.И. Курс гражданского судопроизводства. 2-е изд. СПб., 1876. Т. 1. С. 207-210. процесса как наиболее верного базиса для разрешения гражданско-правовых конфликтов. Возрождение состязательной модели гражданского процесса было подготовлено исторически. Как отмечал И.Г. Щегловитов, крушение прежнего судоустройства и инквизиционного процесса произошло во времена Французской революции ${ }^{4}$. Поэтому неудивительно, что именно во Франции был принят гражданскопроцессуальный кодекс нового образца, закрепивший в основе судопроизводства состязательность, диспозитивность, независимость суда, минимизацию его роли в процессе. Французский кодекс стал эталоном гражданскопроцессуального закона на долгое время для многих государств. Как отмечают некоторые зарубежные исследователи, его популярность была обусловлена тем фактом, что он отвечал потребностям XIX века и заключил в себе достаточно много общеевропейских традиций ${ }^{5}$.

Развитие идей субъективного права привело к появлению вопроса о пределах его осуществления и наилучших механизмах защиты, к появлению в гражданском процессе серьезной дискуссии между представителями «либеральной» и «социальной» моделей гражданского процесса 6 . Эта дискуссия породила внутри состязательной модели два течения, преобразовавшихся в два типа: либеральный подход или либеральный тип, отраженный в французском гражданском процессуальном кодексе (Code de procédure civile 1806г.), и социальный подход или социальный тип, закрепившийся в австрийском гражданском процессуальном кодексе (Austrian Zivilprozessordnung 1895г.).

Россию этот процесс также не обошел стороной. Коренное преобразование гражданского судопроизводства в нашей стране связано с принятием Устава гражданского судопроизводства 1864 года (далее - УГС) 7 . В ходе его разработки был изучен опыт многих стран. Однако Франция с конца XVIII века и большую часть следующего столетия была законодательницей моды не только на наряды, но и на законодательство. Стоит заметить, что ее гражданский процессуальный кодекс оставался одним из

\footnotetext{
Щегловитов И.Г. Влияние иностранных законодательств на составление Судебных уставов 20 ноября 1864 года. Петроград, 1915. С.16.
}

R.C. van Caenegem History of European Civil Procedure//International Encyclopedia of Comparative Law (Volume XVI: Civil Procedure, Chapter 2). 1973. P. 91.

6 Аболдин В.О. О развитии гражданского процесса через смену основной парадигмы (начало) // Арбитражный и гражданский процесс. 2012. №11. С. 42.

Свод законов Российской империи. Книга пятая. Том XVI. Устав гражданского судопроизводства. С.-Петербург, 1912. 
лучших актов своего времени. Поэтому неудивительно, что «при реформе гражданского процесса взяли за образец наиболее рациональную систему - французскую...» ${ }^{8}$. Приняв французскую систему, Россия приняла и либеральный тип состязательной модели процесса. Однако в дальнейшем в процессе реформирования гражданского судопроизводства в конце XIX века и принятием законов о введении понудительного исполнения и упрощенного судопроизводства российский гражданский процесс приобрел черты, свойственные уже социальному типу, что отразило общемировую тенденцию развития гражданского судопроизводства.

Таким образом, история гражданского судопроизводства может быть разделена на три этапа: состязательный процесс, следственный (инквизиционный) процесс, затем с XIX века состязательный процесс, который эволюционно разделился на два типа: либеральный и социальный.

В российской историко-правовой и гражданско-процессуальной науке вопрос либерального и социального процесса практически не изучен, поэтому при выделении основных признаков этих типов стоит обращаться к работам зарубежных исследователей, которые выделяют такие черты социального типа, как: расширение полномочий суда в процессе (case-management); отказ от обязательного ответа на иск; запрет совершать процессуальные действия после истечения отведенного на них срока; выделение письменной подготовительной и устной основной частей в судопроизводстве 9 . На наш взгляд, стоит остановиться только на двух характеристиках социального процесса: расширение полномочий суда в процессе (case-management); отказ от обязательного ответа на иск.

Относительно запрета совершать процессуальные действия после истечения отведенного на них срока стоит сказать, что этот принцип является частью положений о полномочиях суда, поскольку если суд контролирует ход процесса и следит за всеми сроками, следовательно, то ему предоставляется возможность указать сторонам на их пропуск и отказать на этом основании в удовлетворении их ходатайств. Если же стороны преимущественно «ведут» процесс, то и за соблюдением сроков следят они сами.

Выделение устной и письменной частей уже нашло свое отражение в общих принципах ренессанса состязательной модели процесса в целом, и

\footnotetext{
8 Васьковский Е.В. Учебник гражданского процесса. 2-е изд., перераб. М., 1917. С. 162.

Kralik W.. Die Verwirklichung der Ideen Franz Kleins in der Zivilprozessordnung von 1895. in: Hofmeister (ed.), o.c. P. $94-95$.
}

нельзя сказать, что это положение определяет особенность социального процесса как такового.

Кроме того, из характеристик социального типа можно также выделить и критерии для сравнения его с либеральным типом, а именно: полномочия суда в процессе; предварительная защита ответчика; уведомление сторон о переданных в суд документах.

Либеральный тип состязательной модели исходит из понимания гражданского процесса как борьбы независимых граждан, которые самостоятельно выбирают путь решения их кон-

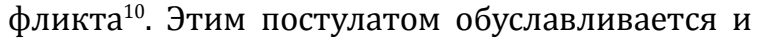
место суда как независимого и беспристрастного арбитра. Суду предоставляются минимальные полномочия в процессе. Соответственно, его главными героями являются стороны.

Внимание социального типа состязательной модели концентрируется на понимании социальной функции (Sozialfunction) процесса, а именно, что разрешение конкретного гражданского дела не является единственной целью гражданского судопроизводства, он также должен служить общему благу ${ }^{11}$. Государство выступает как представитель интересов всего социума и создает необходимые механизмы для удовлетворения потребностей в предоставлении судебной защиты прав и законных интересов. Посредством разрешения конкретного конфликта суд удовлетворяет потребности не только спорящих субъектов, но и общества, заинтересованного в отсутствии конфликтов как таковых.

Таким образом, из различного понимания сущности гражданского процесса вытекает главный критерий разграничения либерального и социального типов: полномочия суда в процессе. Данный параметр можно рассмотреть с двух позиций: полномочия по участию в подготовке дела и обмену процессуальными бумагами; полномочия по контролю за процессуальными сроками.

Особенностью либерального типа является устранение суда от участия в стадии подготовки дела. Главными героями здесь являются стороны. Французский кодекс гражданского судопроизводства закреплял, что «приготовление дела совершается посредством бумаг, сообщаемых взаимно защитниками тяжущихся через судебных приставов, без всякого участия суда» ${ }^{12}$. А. Оскольский поддерживал данную

10 C.H. van Rhee European Traditions in Civil Procedure. Antwerp: Intersentia, 2005. P. 6

11 Там же.

12 Оскольский А. Состязательный процесс в Уставе гражданского судопроизводства 20 ноября 1864 года // Журнал гражданского и уголовного права. 1880. Кн. III. C. 29. 
позицию и указывал, что посредничество суда отвлекает самих судей от их главной обязанности, то есть решения дел ${ }^{13}$. Ему возражали проф. Малышев и проф. Анненков, которые разделяли позицию, что движение процесса должно совершаться в законных формах и на суде должна лежать обязанность по наблюдению за их законностью, суд не должен ждать указаний на их совершение или понуждения к ним от сторон ${ }^{14}$. Суд как орган власти должен санкционировать стороны на совершение действий, а не на оборот. Таким образом, этот подход исследователей соответствует социальной концепции гражданского процесса.

УГС в статьях 305 и 308 допускал два порядка обмена состязательными бумагами: через суд и самостоятельно. То есть сами стороны избирали путь процессуального «общения», это позволяет заключить, что возникновение полномочий суда как субъекта подготовительной стадии зависело здесь от воли самих тяжущихся, что отражает либеральный подход.

Рассмотренные положения УГС, регламентирующие полномочия суда в гражданском судопроизводстве, являются отражением принятого либерального типа состязательной модели. Действия суда как субъекта управления процессом подчинены воле сторон.

В упрощенном порядке согласно статье 365.7 УГС суд, признав дело подлежащим разрешению в этом порядке, вызывал ответчика к разбору дела. Как таковая стадия подготовки дела в этом порядке именно повесткой о вызове и ограничивалась. Обмена процессуальными бумагами не было, что обуславливалось бесспорным характером дел.

Дела в упрощенном порядке разрешались судьей единолично. Полномочия суда здесь шире, чем в обычном разбирательстве. На суд возлагалась обязанность признать дело, подлежащим разбирательству в упрощенном порядке. Однако поскольку данная процедура могла быть применена только по ходатайству истца, то ее введение в гражданский процесс не нарушает общих принципов состязательности, но выходит за рамки либерального типа данной модели. Полномочия суда по ее санкционированию можно назвать контрольными, призванными обеспечить защиту интересов сторон и общества в целом. Кроме того, во избежание злоупотреблений со стороны истца перед судом стоит задача проверить факт отсутствия спора о праве, поскольку

13 Указ. соч. С. 34.

14 Анненков К. Усмотрение суда в гражданском процессе // Журнал гражданского и уголовного права. 1889. Кн.III - IV. C. 69. этот вопрос является ключевым для выбора процедуры разрешения дела. Некоторые бесспорные на первый взгляд дела при более детальном изучении оказываются обремененными спором о праве.

Понудительное исполнение, так же как и упрощенное производство, являлись изъятиями из общего порядка, предусмотренного УГС. Оно инициировалось взыскателем. Суд или земский начальник согласно ст. 149 УГС без вызова ответчика делал санкционирующую надпись на самом ходатайстве. Далее согласно статье 151 от взыскателя зависело обратить этот акт к исполнению или нет. Таким образом, в этой процедуре наличествует диспозитивность заявителя как основа состязательной модели гражданского судопроизводства. Однако имеются и особенности этого производства, ставящие его особняком в гражданском процессе. Прежде всего, это отсутствие ответчика в процессе. Производство проходило без его участия, но обуславливалось особым характером дела: отсутствие спора о праве и наличие актов, подтверждающих неисполнение обязательств. Кроме того, суть этого производства заключалась, по справедливому замечанию T.М. Яблочкова, в том, что суд дает «ехеquatur», то есть снабжает акт исполнительной силой. Суд выступает как орган государства, выполняющий, прежде всего, функции защиты взыскателя от неисполнения ответчиком обязательств. Как видно, роль его в данной процедуре не в разрешении конфликта, а именно в социальной защите через принуждение недобросовестной стороны.

Оценки этих процедур современниками были достаточно сдержанными. Е.В. Васьковский отмечал, что «те порядки, которые называются изъятиями из общего порядка, имеют, безусловно, обязательное значение, так что подлежащие им дела ни в каком случае не могут быть разбираемы в общем порядке. Напротив, понудительный и исполнительный порядки - факультативны» ${ }^{15}$. В настоящее время, в начале XXI века В.В. Захаров делает вывод о том, что «цель данных преобразований состояла в обретении оптимального соотношения в судебном процессе между результатом и способом его достижения» ${ }^{16}$. На наш взгляд, новые виды производств основывались на общих принципах состязательной модели, но полномочия суда распределялись в них по-иному, суд в них выполнял уже роль не только и не столь-

\footnotetext{
15 Васьковский Е.В. Указ. соч. С. 213.

6 Захаров В.В. Реформирование отечественного гражданского судопроизводства в конце XIX в. // История государства и права. 2012. № 15. С. 22.
} 
ко арбитра, сколько государственного органа, защищающего интересы общества.

При либеральном типе за соблюдением сроков следят сами стороны. Гражданско-процессуальный закон устанавливает, безусловно, процессуальные сроки, но следят за их соблюдением сами истцы и ответчики. Это приводит к тому, что сам по себе пропуск срока не является основанием для суда не производить дальнейших действий по движению процесса, если противная сторона не заявит об этом пропуске ${ }^{17}$. УГС устанавливал сроки совершения процессуальных действий по подготовке дела, в частности, срок явки в суд и представление к этому сроку состязательных бумаг. В статьях 320 и 321 УГС устанавливалось, что с пропуском стороной срока на представление объяснения другая сторона может просить председателя суда о назначении слушания дела, а также если срок на представление опровержения истек, то любая сторона может обратиться к председателю о назначении слушания. Эти положения указывают, что в общем порядке суд был устранен от контроля за сроками совершения процессуальных действий.

Исключение составлял сокращенный порядок, где суд наделялся правом устанавливать для сторон сроки для явки в суд, что затем распространилось на упрощенный порядок с дополнением, что срок этот должен быть самым кратким. При понудительном исполнении суд, признав дело подлежащим рассмотрению в этом порядке, сразу совершал необходимые действия. Таким образом, в отличие от общего порядка, соответствующего либеральному типу, упрощенный и понудительный порядки предоставляли суду полномочия по назначению сроков и их контролю, что внесло изменения в сложившуюся систему и привело к проникновению социального типа в судопроизводства.

Как уже было отмечено, обязательным элементом либерального типа состязательной модели является обязанность ответчика представить ответ на иск. Это положение нашло закрепление в статье 313 УГС, по которой ответчик обязан был представить ответ на иск. В процедуре понудительного исполнения должника вовсе не привлекали в процесс, соответственно, отзыва он не представлял. Упрощенное производство также отказалось от этой обязанности ответчика, что было связано с сокращением процессуальных сроков в этой процедуре, а предоставление ответчиком ответа на иск сопряжено с дополнительными временными затратами в процессе. Здесь стоит отметить, что и понудительное исполнение и упрощенное производство были реакцией на возросший экономический оборот, ввиду чего увеличилось количество несложных бесспорных дел, разбирательство по которым только тормозило его.

Таким образом, введенные процедуры не предусматривали обязанности ответчика представить ответ на иск, что указывает на проникновение в гражданское судопроизводство элементов социального типа состязательной модели.

Обобщая изложенное выше, можно сделать вывод о том, что УГС 1864 года кардинально изменил гражданское судопроизводство в России, возвратив в него состязательное начало, что, в свою очередь, привело к смене модели процесса. Исторически гражданский процесс пережил к 1864 году два цикла: состязательная модель, затем господство следственной (инквизиционной) модели и восстановление состязательной в 1864 году. Однако состязательная модель к концу XIX века в своем развитии также прошла два этапа: этап либерального типа состязательной модели и этап социального типа состязательной модели. Первый этап - 1864 года по 1889 год, который связан с пониманием процесса как борьбы независимых сторон, каждая из которых должна была доказать свою позицию, исход дела во многом зависел от них самих. Второй этап - с 1889 года по начало XX века, когда произошло изменение понимания сущности самого процесса, законодатель стал также обращать внимание на социальную роль процесса, помогающего развитию общества и экономики, поэтому многие институты и элементы процесса были упразднены или пересмотрены.

\section{Библиография:}

1. Решетникова И.В. Судебные реформы XIX и XXI вв. в области гражданского судопроизводства // Кодификация российского частного права / под ред. Д.А. Медведева. М., 2008.

2. Фокина М.А. Состязательный гражданский процесс в феодальной России // Правоведение. 1999. № 1.

3. Малышев К.И. Курс гражданского судопроизводства. 2-е изд. СПб., 1876. Т. 1.

4. Щегловитов И.Г. Влияние иностранных законодательств на составление Судебных уставов 20 ноября 1864 года. Петроград, 1915.

\footnotetext{
17 Оскольский А. Указ соч. С. 36.
} 
5. R.C. van Caenegem History of European Civil Procedure//International Encyclopedia of Comparative Law (Volume XVI: Civil Procedure, Chapter 2). 1973.

6. Аболдин В.О. О развитии гражданского процесса через смену основной парадигмы (начало) // Арбитражный и гражданский процесс. 2012. № 11.

7. Васьковский Е.В. Учебник гражданского процесса. 2-е изд., перераб. М., 1917.

8. Kralik W.. Die Verwirklichung der Ideen Franz Kleins in der Zivilprozessordnung von 1895. in: Hofmeister (ed.), o.c.

9. C.H. van Rhee European Traditions in Civil Procedure. Antwerp: Intersentia, 2005..

10. Оскольский А. Состязательный процесс в Уставе гражданского судопроизводства 20 ноября 1864 года // Журнал гражданского и уголовного права. 1880. Кн. III.

11. Анненков К. Усмотрение суда в гражданском процессе // Журнал гражданского и уголовного права. 1889. Кн. III-IV.

12. Захаров В.В. Реформирование отечественного гражданского судопроизводства в конце XIX в. // История государства и права. 2012. № 15.

\section{References:}

1. Reshetnikova I.V. Sudebnye reformy KhIKh i KhKhI vv. v oblasti grazhdanskogo sudoproizvodstva // Kodifikatsiya rossiiskogo chastnogo prava/ Pod red. D.A. Medvedeva. M. 2008.

2. Fokina M.A. Sostyazatel'nyi grazhdanskii protsess v feodal'noi Rossii // Pravovedenie. 1999. № 1.

3. Malyshev K.I. Kurs grazhdanskogo sudoproizvodstva. 2-e izd. SPb., 1876. T. 1.

4. Shcheglovitov I.G. Vliyanie inostrannykh zakonodatel'stv na sostavlenie Sudebnykh ustavov 20 noyabrya 1864 goda. Petrograd. 1915.

5. R.C. van Caenegem History of European Civil Procedure // International Encyclopedia of Comparative Law (Volume XVI: Civil Procedure, Chapter 2). 1973.

6. Aboldin V.O. O razvitii grazhdanskogo protsessa cherez smenu osnovnoi paradigmy (nachalo) // Arbitrazhnyi i grazhdanskii protsess. 2012. №11.

7. Vas'kovskii E.V. Uchebnik grazhdanskogo protsessa. 2-e izd., pererab. M., 1917.

8. Kralik W.. Die Verwirklichung der Ideen Franz Kleins in der Zivilprozessordnung von 1895. in: Hofmeister (ed.), o.c.

9. C.H. van Rhee European Traditions in Civil Procedure. Antwerp: Intersentia, 2005..

10. Oskol'skii A. Sostyazatel'nyi protsess v Ustave grazhdanskogo sudoproizvodstva 20 noyabrya 1864 goda // Zhurnal grazhdanskogo i ugolovnogo prava. 1880. Kn. III.

11. Annenkov K. Usmotrenie suda v grazhdanskom protsesse // Zhurnal grazhdanskogo i ugolovnogo prava. 1889. Kn. III-IV.

12. Zakharov V.V. Reformirovanie otechestvennogo grazhdanskogo sudoproizvodstva v kontse XIX v. // Istoriya gosudarstva i prava. 2012. № 15.

Материал поступил в редакцию 26 февраля 20142. 